\title{
THE SPAWNING BEHAVIOUR OF PLAICE
}

\author{
By G. R. Forster \\ The Plymouth Laboratory
}

On the evening of 20 February 1953, two plaice (Pleuronectes platessa L.) in the largest tank of the Aquarium were observed spawning. No information on the spawning behaviour of pleuronectids has been found in the literature; nevertheless, the observation may very well not be original, but is considered of sufficient interest to justify an account of it.

The two plaice were swimming in mid-water about $2 \mathrm{ft}$. 6 in. from the bottom, the female lying slightly diagonally across the back of the male their vents being close together. The female, considerably larger than the male, was quivering violently and emitting a rapid stream of eggs. Mr F. J. Warren who was also watching the tank saw a stream of milt coming from the male. After about $20 \mathrm{sec}$. the fish separated and settled on the bottom. The eggs were being eaten very rapidly by a shoal of sea-bream (Pagellus centrodontus de la Roche). The beginning of the spawning was not seen but the whole act did not take much longer than three-quarters of a minute as the tank had been under observation about half a minute earlier. When captured afterwards the female was found to be almost completely spent, but may have spawned previously. Fertilized eggs from subsequent spawnings by other plaice were taken in the tank for the next 3 days, between 6 and 9 p.m., though the actual spawning was never again observed. 